\title{
FAKTOR-FAKTOR YANG MEMPENGARUHI KEJADIAN PUTUS BEROBAT PADA KASUS TB MDR/RR DI DKI JAKARTA TAHUN 2014- 2015
}

\section{Contributing Factors of Loss to Follow Up among MDR/RR TB Cases in DKI Jakarta 2014-2015}

\author{
Helmi Suryani Nasution ${ }^{1}$, Tri Yunis Miko Wahyono ${ }^{2}$ \\ ${ }^{1}$ Program Studi Ilmu Kesehatan Masyarakat Fakultas Kedokteran dan Ilmu Kesehatan Universitas \\ Jambi \\ ${ }^{2}$ Departemen Epidemiologi Fakultas Kesehatan Masyarakat Universitas Indonesia
}

\begin{abstract}
Abstrak
Salah satu tantangan program TB di Indonesia adalah semakin meningkatnya trend angka putus berobat pada pasien TB MDR/RR. Pada tahun 2011-2015, angka putus berobat berada di rentang 25-30\%. Angka ini juga berada di atas angka putus berobat global DKI Jakarta merupakan salah satu provinsi yang memiliki jumlah kasus TB (termasuk TB MDR/RR) yang cukup besar. Sebagai provinsi dengan jumlah kasus yang besar, belum ada penelitian di DKI Jakarta mengenai faktor-faktor yang menyebabkan kejadian putus berobat pada pasien TB MDR/RR. Desain penelitian ini adalah kohort retrospektif. Data bersumber dari kasus TB MDR/RR di DKI Jakarta yang tercatat di E-TB Manager yang memulai pengobatan di tahun 2014-2015. Analisis statisik menggunakan uji Chi-Square. Ukuran asosiasi yang digunakan adalah risiko relative (RR).

Angka putus berobat pasien TB MDR/RR di DKI Jakata tahun 2014-2015 adalah 37,1\%. Umur diketahui berhubungan secara statistik dengan kejadian putus berobat sedangkan jenis kelamin, riwayat pengobatan TB, dan status HIV tidak berhubungan dengan kejadian putus berobat.

Kata Kunci: kohort retrospektif, resisten obat, perilaku pencarian pengobatan
\end{abstract}

\begin{abstract}
One of the challenges of TB programs in Indonesia is the increasing trend of loss to follow up among MDR/RR-TB cases. In 2011-2015, the loss to follow up was in the range of 25-30\%. This figure is above the global rate for loss to follow up. DKI Jakarta is one of the provinces that has a large number of TB cases (including MDR/RR-TB cases). As a province with a large number of cases, there has been no research in DKI Jakarta regarding the factors contributing to loss to follow up of treatment among MDR/ RR-TB patients. The study design was a retrospective cohort. The source of data came from MDR/RR-TB cases in DKI Jakarta recorded in the E-TB Manager who started treatment in 2014-2015. Statistical analysis used was the Chi-Square test. The association measurement was a relative risk (RR).

The loss to follow up among MDR/RR-TB patients in DKI Jakarta in 2014-2015 was 37.1\%. Age was known to be statistically associated with the incidence of loss to follow up while sex, history of TB treatment, and HIV status were not associated with the incidence of loss to follow up.
\end{abstract}

Keywords: retrospective cohort, drug resistance, health seeking behavior

Korespondensi : Helmi Suryani Nasution

Email : helmisuryani@unja.ac.id

\section{PENDAHULUAN}

TB multi-drug resistant (MDR) adalah tuberkulosis yang disebabkan oleh organisme yang resistan sedikitnya terhadap isoniazid $(\mathrm{H})$ dan rifampisin $(\mathrm{R})$ sedangkan TB resistan rifampisin (RR) terjadi ketika kuman TB resistan terhadap rifampisin dengan atau tanpa resistansi 
terhadap OAT lain $(1,2)$. Isoniazid dan rifampisin merupakan obat utama dari kemoterapi jangka pendek. Isoniazid merupakan bakterisidal yang poten, tidak mahal, orally active, dan memiliki reaksi efek samping yang lebih sedikit. Oleh karena itu, isoniazid digunakan untuk durasi rejimen pengobatan apapun kecuali jika ada kontraindikasi atau resistansi. Rifampisin juga bakterisidal, memiliki aktivitas strerilisasi yang sangat baik, mencegah munculnya resistansi terhadap obat lain, cepat diserap oleh saluran pencernaan, dan relatif tidak toksik (3).

TB paru sensitif obat dapat diobati secara efektif hanya dengan $\mathrm{H}$ dan $\mathrm{R}$ selama 9 bulan. Tambahan pirazinamid (Z) selama dua bulan pertama memperpendek durasi pengobatan menjadi 6 bulan. Rejimen pengobatan jangka pendek yang terdiri dari 4-5 obat masih efektif dengan adanya resistansi $\mathrm{H}$ dan atau streptomycin (S). Berbeda dengan monoresistan terhadap $\mathrm{H}$ atau $\mathrm{R}$ yang dapat diobati dengan mudah dan efektif dengan OAT lini pertama, kombinasi resistan $\mathrm{H}$ dan $\mathrm{R}$ membutuhkan pengobatan dengan setidaknya 4 rejimen obat termasuk quinolone dan obat injeksi (yaitu aminoglycoside atau capreomycin). Rejimen ini digunakan selama 18-24 bulan, memiliki banyak efek samping, membutuhkan biaya US\$1.850-US\$ 9.190 per orang, dan efektivitasnya kurang (3). Manajemen dan pengobatan TB MDR juga kompleks karena biaya pengobatan yang tinggi, penggunaan OAT yang sangat toksik dengan efek samping potensial, waktu pengobatan yang lebih panjang, serta meningkatnya kegagalan pengobatan dan angka kematian (4-8).

Salah satu tantangan program Manajemen Terpadu Pengendalian TB
Resistan Obat (MTPTRO) di Indonesia adalah angka loss to follow up (putus berobat) dan angka kematian pasien TB resistan obat yang meningkat secara signifikan. Dari data Subdirektorat Tuberkulosis Kementerian Kesehatan, terlihat bahwa secara umum trend angka putus berobat pasien TB resisten obat menunjukkan peningkatan. Di tahun 2011, angka putus berobat pasien TB resistan obat adalah $25 \%$, lalu naik menjadi $27 \%, 29 \%$, 28\%, dan 30\% di tahun 2012-2015 secara berturut-turut (9). Pasien TB MDR yang putus berobat atau gagal pengobatan mengalami peningkatan risiko untuk resistansi obat yang lebih berat, meninggalkan beberapa pilihan pengobatan, dan juga cenderung untuk mengalami peningkatan morbiditas dan mortalitas karena TB, serta berkontribusi terhadap penularan TB resistan obat di masyarakat (10).

DKI Jakarta merupakan salah satu provinsi yang mengobati pasien TB resistan obat relatif banyak. Pada tahun 2018, terdapat 29.857 kasus TB yang terdaftar dan diobati (11). Di provinsi tersebut, terdapat RSUP Persahabatan yang menjadi RS uji pendahuluan TB resistan obat di Indonesia pada tahun 2009 (12). Dengan meningkatnya tren proporsi putus berobat pada pasien TB resistan obat dan belum ada penelitian yang dilakukan di DKI Jakarta mengenai hal ini, maka penelitian ini dilakukan untuk mengetahui faktor-faktor yang mempengaruhi kejadian putus berobat pada pasien TB MDR/RR di DKI Jakarta tahun 2014-2015 yang meliputi jenis kelamin, umur, riwayat pengobatan TB, dan status HIV. 


\section{METODE}

Penelitian ini merupakan penelitian deskriptif observasional dengan menggunakan desain kohort retrospektif. Sumber data berasal dari data surveilans TB resistan obat yaitu E-TB Manager yang tersedia di Subdit TB Kementerian Kesehatan. Populasi target pada penelitian ini adalah semua kasus TB MDR/RR di DKI Jakarta yang memulai pengobatan di tahun 2014-2015 sedangkan populasi sumber pada penelitian ini adalah semua kasus TB MDR/RR di DKI Jakarta yang memulai pengobatan di tahun 2014-2015 dan tercatat di E-TB Manager. Populasi eligible pada penelitian ini adalah semua pasien TB MDR/RR yang berdomisili di DKI Jakarta yang tercatat di E-TB Manager, memulai pengobatan di tahun 2014-2015, dan memenuhi kriteria inklusi. Adapun kriteria inklusi penelitian ini yaitu pasien $\mathrm{TB}$, berusia $\geq 15$ tahun, pasien $\mathrm{TB}$ yang terkonfirmasi secara bakteriologis (yaitu pasien dengan hasil pemeriksaan kultur positif atau mikroskopis positif atau mikroskopis negatif atau scanty tetapi hasil TCM menunjukkan rifampisin sensitif atau resistan), pasien TB MDR/RR yang terkonfirmasi baik dengan hasil pemeriksaan DST konvensional dan atau dengan menggunakan pemeriksaan tes cepat (TCM), serta hasil akhir pengobatannya diketahui. Jumlah sampel dalam penelitian ini adalah 420 kasus.

Data E-TB Manager merupakan hasil penginputan data yang bersumber dari formulir TB resistan obat yang ada di fasyankes yaitu TB.06 MDR, TB.05 MDR, TB.04 MDR, dan TB.01 MDR. Data yang dicatat di formulir manual kemudian dimasukkan ke dalam E-TB Manager berbasis web yang kemudian terlaporkan ke Dinas Kesehatan Kabupaten/Kota, Dinas Kesehatan Provinsi, dan Kementerian Kesehatan. Data yang sudah dimasukkan ke dalam E-TB Manager kemudian dapat dieksport ke dalam bentuk excel untuk diolah lebih lanjut dengan software pengolah data.

Analisis univariat dilakukan dengan menampilkan proporsi dari variabel independen dan dependen. Sementara itu, analisis bivariat dilakukan untuk melihat kemaknaan secara statistik menggunakan uji Chi-square. Ukuran asosiasi yang digunakan adalah risiko relatif (RR). Data diolah menggunakan STATA versi 12 .

\section{HASIL PENELITIAN}

Dari 689 kasus yang ada di populasi sumber, 420 kasus (62,9\%) merupakan populasi eligible. Semua populasi eligible diikutsertakan dan dianalisis. Dari 420 kasus TB MDR/RR, 156 kasus $(37,1 \%)$ putus berobat dan 264 kasus $(62,9 \%)$ tidak putus berobat yang terdiri dari pasien sembuh, pengobatan lengkap, gagal, dan meninggal. Gambaran tahap pengambilan sampel dapat dilihat pada bagan berikut. 


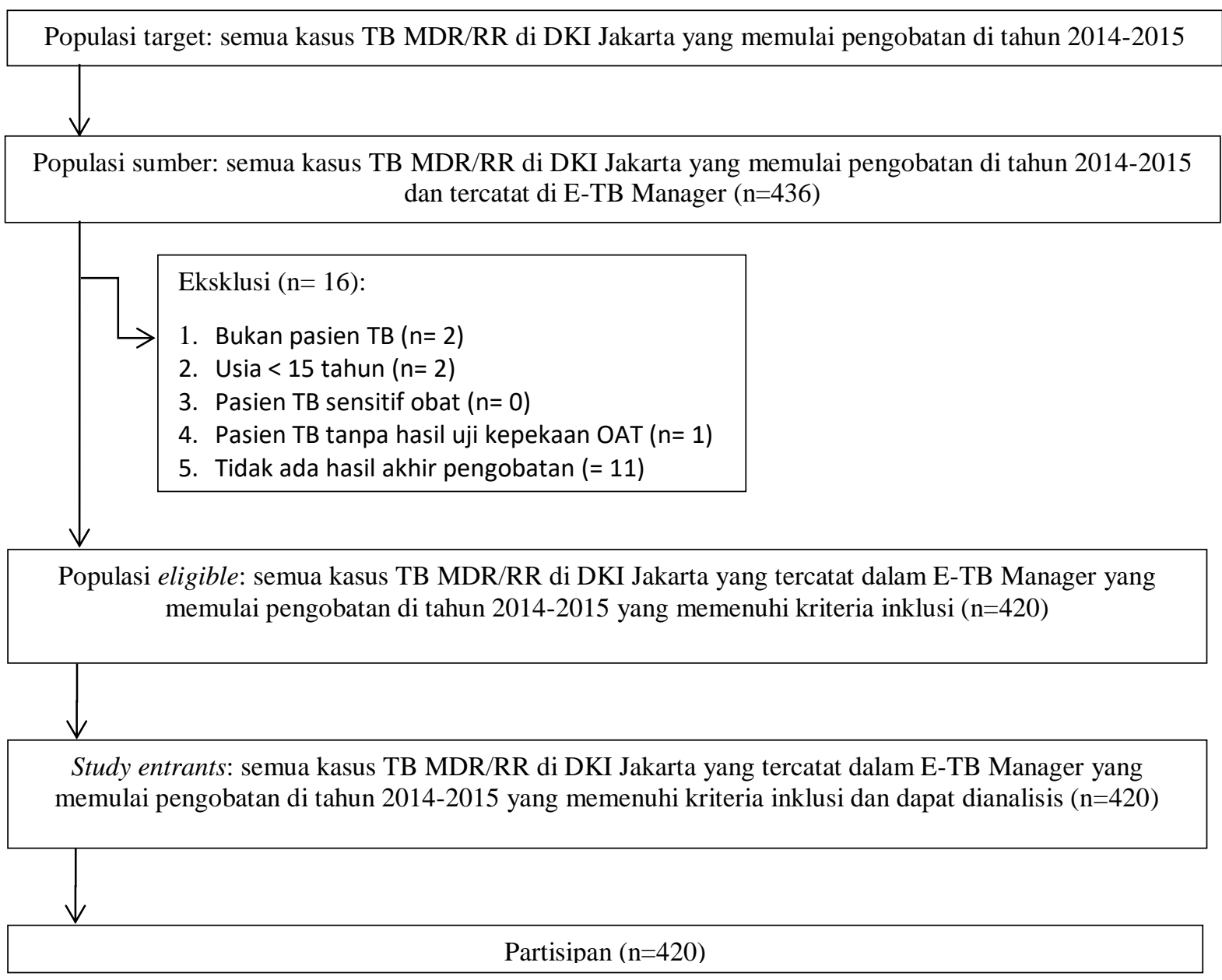

\section{Bagan 1. Proses Pengambilan Sampel}

Pasien dengan jenis kelamin laki-laki lebih banyak dibandingkan perempuan yaitu sebanyak $258(61,43 \%)$ pasien. Jika dilihat dari umur, pasien dengan kelompok umur $\leq 40$ tahun sebanyak $216(51,43 \%)$ pasien. Berdasarkan riwayat pengobatan TB, hanya $17(4,05 \%)$ pasien yang merupakan kasus baru. Sisanya yaitu sebanyak 403 (95,95\%) pasien merupakan pasien pengobatan ulang. Jika dilihat dari status HIV, hanya $14(3,33 \%)$ pasien dengan status HIV positif. Sisanya yaitu sebanyak 406 (96,67\%) pasien status HIV negatif atau tidak diketahui.

Pada pasien yang putus berobat, persentase pasien laki-laki yang putus berobat $(38,76 \%)$ sedikit lebih banyak dibandingkan pada pasien perempuan $(34,57 \%)$. Persentase pasien yang berusia > 40 tahun $(43,14 \%)$ lebih banyak yang putus berobat dibandingkan yang berusia $\leq 40$ tahun $(31,48 \%)$. Persentase pasien dengan riwayat pengobatan TB baru $(47,06 \%)$ lebih banyak yang putus berobat dibandingkan pasien dengan riwayat pengobatan TB pengobatan ulang $(36,72 \%)$. Jika dilihat dari status HIV, persentase pasien TB dengan status HIV negatif/tidak diketahui $(37,44 \%)$ lebih banyak dibandingkan dengan pasien HIV positif $(28,57 \%)$. 
Tabel 1. Karakteristik Responden

\begin{tabular}{|c|c|c|c|c|}
\hline \multirow{2}{*}{ Variabel } & \multicolumn{2}{|c|}{ Putus berobat } & \multicolumn{2}{|c|}{ Tidak putus berobat } \\
\hline & $n=156$ & $\%$ & $n=264$ & $\%$ \\
\hline \multicolumn{5}{|l|}{ Jenis Kelamin } \\
\hline Perempuan & 56 & 34,57 & 106 & 65,43 \\
\hline Laki-laki & 100 & 38,76 & 158 & 61,24 \\
\hline \multicolumn{5}{|l|}{ Umur } \\
\hline$\leq 40$ tahun & 68 & 31,48 & 148 & 68,52 \\
\hline$>40$ tahun & 88 & 43,14 & 116 & 56,86 \\
\hline \multicolumn{5}{|c|}{ Riwayat Pengobatan TB } \\
\hline Baru/tidak diketahui & 8 & 47,06 & 9 & 52,94 \\
\hline Pengobatan ulang & 148 & 36,72 & 255 & 63,28 \\
\hline \multicolumn{5}{|l|}{ Status HIV } \\
\hline Negatif/tidak diketahui & 152 & 37,44 & 254 & 62,65 \\
\hline Positif & 4 & 28,57 & 10 & 71,43 \\
\hline
\end{tabular}

Dari hasil analisis bivariat, diketahui bahwa variabel yang berpengaruh terhadap kejadian putus berobat di DKI Jakarta tahun 2014-2015 adalah umur dengan p-value sebesar 0,01 dan RR 1,37 (95\%CI 1,061,76). Sementara itu, variabel jenis kelamin, riwayat pengobatan $\mathrm{TB}$, dan status HIV tidak berpengaruh terhadap kejadian putus berobat di mana $p$-value $>0,05$. Hasil perhitungan analisis bivariat dapat dilihat pada tabel 2 di bawah ini.

Tabel 2. Analisis Bivariat dan Risiko Relatif antara Variabel Independen dan Dependen

\begin{tabular}{lrrr}
\hline \multicolumn{1}{c}{ Variabel } & $\begin{array}{c}\text { Point } \\
\text { Estimate }\end{array}$ & 95\%CI & P-value \\
\hline Jenis Kelamin & Reff & & \\
$\begin{array}{l}\text { Perempuan } \\
\text { Laki-laki }\end{array}$ & 1,12 & $0,86-1,46$ & 0,39 \\
Umur & & & \\
$\leq 40$ tahun & Reff & & \\
$>40$ tahun & 1,37 & $1,06-1,76$ & 0,01 \\
Riwayat Pengobatan TB & & & \\
Baru/tidak diketahui & Reff & & \\
Pengobatan ulang & 0,78 & $0,46-1,31$ & 0,39 \\
Status HIV & & & \\
Negatif/tidak diketahui & $R e f f$ & & \\
Positif & 0,76 & $0,33-1,76$ & 0,49 \\
\hline
\end{tabular}

\section{PEMBAHASAN}

Persentase pasien TB MDR/RR yang putus berobat lebih besar dari angka putus berobat TB MDR/RR di tingkat nasional. Tingginya angka putus berobat pada pasien
TB MDR/RR mengakibatkan target angka keberhasilan pengobatan tidak tercapai yaitu minimal $90 \%$ di tingkat global dan $85 \%$ di tingkat nasional. Tingginya angka putus berobat ini akan menyebabkan 
terganggunya program pengendalian TB nasional. Pasien TB MDR yang putus berobat atau gagal pengobatan mengalami peningkatan risiko untuk resistansi obat yang lebih berat, meninggalkan beberapa pilihan pengobatan, dan juga cenderung untuk mengalami peningkatan morbiditas dan mortalitas karena TB, serta berkontribusi terhadap penularan TB resistan obat di masyarakat (10).

Variabel umur berhubungan secara statistik dengan kejadian putus berobat pada pasien TB MDR/RR di Jakarta dengan nilai RR sebesar RR 1,37 (95\%CI 1,061,76). Angka ini menunjukkan bahwa pasien dengan usia > 40 tahun memiliki risiko 1,37 kali untuk putus berobat dibandingkan pasien berusia $\leq 40$ tahun. Hal ini sejalan dengan beberapa penelitian yang menyebutkan bahwa usia tua merupakan faktor risiko terjadinya putus berobat seperti pada penelitian yang dilakukan di Afrika Selatan dan Uzbekistan. Penelitian yang dilakukan pada pasien TB MDR dan XDR di Uzbekistan diketahui bahwa odds pada pasien yang berusia > 45 tahun 1,77 (95\% CI 1,10-2,87) kali dibandingkan dengan usia $\leq 45$ tahun (13).

Berdasarkan hasil analisis bivariat, variabel jenis kelamin, variabel ini tidak bermakna secara statistik dengan kejadian putus berobat di mana $p$-value 0,39 dan $\mathrm{RR}$ 1,12 (95\%CI 0,86-1,46). Hasil penelitian di Afrika Selatan menyebutkan bahwa odds laki-laki 1,3 kali lebih besar untuk putus berobat dibandingkan perempuan (14). Hasil ini sejalan dengan penelitian yang dilakukan oleh Masini et al. di Kenya yang menyebutkan bahwa laki-laki memiliki risiko yang tinggi terhadap terhentinya pengobatan dengan $\mathrm{HR}$ sebesar 1,46 (95\%CI 1,35-1,58), penelitian di Maroko dengan HR sebesar 1,93 (95\%CI 1,35-2,75)
(15), dan penelitian di Afrika Selatan dengan HR 4,56 (95\% CI 0,96-20,7) (16). Penelitian lain pada pasien TB MDR di Afrika Selatan juga menyatakan bahwa laki-laki memiliki adjusted OR sebesar 1,9 (95\% CI 1,2-3,1) untuk gagal pengobatan (17). Jenis kelamin mungkin dapat berinteraksi dengan umur atau pekerjaan dalam menjelaskan ketidakpatuhan berobat. Systematic review terhadap penelitian kualitatif mengenai kepatuhan pengobatan TB yang dilakukan oleh Munro et al. menyebutkan bahwa ada konflik antara pengobatan dan pekerjaan serta biaya pengobatan (14).

Riwayat pengobatan pasien TB juga tidak berhubungan secara statistik dengan kejadian putus berobat. Padahal berdasarkan penelitian yang dilakukan di Kenya pada pasien TB yang tercatat di tahun 2013-2014, riwayat loss to follow up sebelumnya merupakan faktor risiko independen yang paling besar terhadap terjadinya interupsi pengobatan. Pasien pengobatan ulang memiliki kemungkinan yang lebih besar untuk loss to follow up dibandingkan dengan pasien baru, khususnya pada pasien yang sudah pernah loss to follow up sebelumnya $(\mathrm{HR}=4,79)$ dan pasien kambuh $(\mathrm{HR}=1,70)(18)$. Hal yang sama juga ditemukan pada penelitian di Sri Lanka yang menyatakan bahwa pasien BTA positif yang putus berobat pada pengobatan sebelumnya mempunyai odds 2,4 kali lebih besar untuk putus berobat dibandingkan dengan pasien yang kambuh dengan TB BTA positif yang telah menyelesaikan pengobatan dan dinyatakan sembuh (19). Perbedaan hasil penelitian ini dengan penelitian di negara lain mungkin disebabkan karena adanya misklasifikasi riwayat pengobatan pasien TB sebelumnya. Hal ini mengakibatkan terjadinya bias informasi non-differential. Bias jenis ini 
menyebabkan estimasi asosiasi mendekati null value atau asosiasi antara exposure dengan outcome menjadi underestimate.

Status HIV juga tidak berhubungan secara statistik dengan kejadian putus berobat. Dari data yang diperoleh, terdapat 378 (90\%) pasien memiliki status HIV negatif, $14(3,33 \%)$ pasien merupakan pasien HIV positif, dan sisanya yaitu 28 $(6,67 \%)$ pasien tidak diketahui status HIV nya. Angka ini menunjukkan bahwa hanya $6,67 \%$ yang datanya tidak lengkap. Kejadian putus berobat pada pasien HIV positif dikaitkan dengan reaksi dan efek samping obat. Secara umum angka kejadian reaksi obat yang tidak diinginkan akibat pengobatan TB MDR pada pasien HIV positif lebih tinggi dibanding pasien dengan status HIV negatif (20). Menurut Scano, F. (2008), beberapa isu yang terkait dengan pasien yang mendapatkan ART dan rejimen OAT lini kedua adalah waktu pemberian ART, interaksi obat, dan toksisitas obat. Efek samping OAT dan ART yang mungkin saling tumpang tindih atau terkait (21). Tidak adanya hubungan antara status HIV dan putus berobat mungkin disebabkan karena variabel ini tidak secara langsung berpengaruh terhadap kejadian putus berobat. Variabel efek samping obat mungkin lebih tepat digunakan untuk melihat kejadian putus berobat.

Meskipun terdapat beberapa kelemahan, penelitian ini memiliki beberapa kekuatan. Dengan desain kohort, temporal relationship terjaga. Akan tetapi, dengan desain kohort retrospektif peneliti tidak dapat mengontrol kelengkapan dan kualitas data yang digunakan. Jika dilihat dari segi biaya dan waktu, penelitian dengan desain ini menjadi lebih ekonomis. Pada penelitian ini, kecil kemungkinan bias seleksi terjadi karena semua populasi sumber diikutsertakan dalam penelitian kecuali untuk kasus-kasus yang tidak memenuhi kriteria inklusi. Dengan demikian, semua kasus yang eligible berkesempatan untuk ikut serta dalam penelitian ini.

Hasil penelitian ini memiliki rentang kepercayaan yang relatif sempit atau dapat disimpulkan bahwa peran chance pada penelitian ini kecil. Meskipun peran chance dalam penelitian ini kecil kemungkinanya terjadi, ada hasil perhitungan suatu variabel yang kurang akurat untuk mengeneralisasi hasil perhitungan RR pada populasi target. Hal ini disebabkan karena adanya bias yang mengganggu validitas internal penelitian.

\section{KESIMPULAN DAN SARAN}

Hasil analisis bivariat menunjukkan bahwa umur berhubungan secara statistik dengan kejadian putus berobat pada pasien TB MDR/RR di DKI Jakarta. Sementara itu, variabel jenis kelamin, riwayat pengobatan, dan status HIV tidak berhubungan secara statistik dengan kejadian putus berobat.

Berdasarkan hasil analisis tersebut, Kementerian Kesehatan bersama dengan Dinas Kesehatan Provinsi dan Suku Dinas Kesehatan DKI Jakarta perlu membuat langkah-langkah strategis untuk menurukan angka putus berobat pada pasien TB MDR/RR seperti memfokuskan Komunikasi Informasi dan Edukasi (KIE) yang tersegmentasi pada pasien berusia $>40$ tahun. Selain itu, kelengkapan dan keakuratan data yang dilaporkan di E-TB Manger perlu ditingkatan seperti menambah beberapa variabel yang terkait dengan faktor risiko putus berobat, serta perlu adanya validasi terhadap beberapa variabel misalnya riwayat pengobatan. Petugas harus dilatih agar mampu menggali informasi yang benar dari pasien. Selain itu, 
perlu dilakukan penelitian lanjutan yang menyertakan variabel-variabel lain yang terkait dengan faktor risiko putus berobat dengan jenis penelitian yang berbeda misalnya mixed method.

\section{DAFTAR PUSTAKA}

1. Raviglione MC. Tuberculosis : the essentials. Lung biology in health and disease. 2010. xvi, $390 \mathrm{p}$.

2. WHO. Companion Handbook to the WHO Guidelines for the Programmatic Management of Drug-Resistant Tuberculosis. Companion Handbook to the WHO Guidelines for the Programmatic Management of Drug-Resistant Tuberculosis. 2014. 1-20 p.

3. Bastian I, Portaels F. Multidrugresistant tuberculosis: past, present and future. In: Bastian I, Portlears F, editors. Multidrug-resistant tuberculosis. Kluwer Academic Publishers; 2000.

4. Bonilla CA, Crossa A, Jave HO, Mitnick CD, Jamanca RB, Herrera $\mathrm{C}$, et al. Management of extensively drug-resistant tuberculosis in Peru: cure is possible. PLoS One [Internet]. 2008;3(8):e2957. Available from: http://www.ncbi.nlm.nih.gov/pubme d/18698423\%5Cnhttp://www.pubm edcentral.nih.gov/articlerender.fcgi? artid=PMC2495032

5. Chung-Delgado K, Revilla-Montag A, Guillen-Bravo S, Velez-Segovia E, Soria-Montoya A, Nuñez-Garbin A, et al. Factors associated with anti-tuberculosis medication adverse effects: A case-control study in Lima, Peru. PLoS One. 2011;6(11).

6. Kawai V, Soto G, Gilman RH, Bautista CT, Caviedes L, Huaroto L, et al. Tuberculosis mortality, drug resistance, and infectiousness in patients with and without HIV infection in Peru. Am J Trop Med Hyg. 2006;75(6):1027-33.
7. Santha T, Garg R, Frieden TR, Chandrasekaran V, Subramani R, Gopi PG, et al. Risk factors associated with default, failure and death among tuberculosis patients treated in a DOTS programme in Tiruvallur District, South India, 2000. Int J Tuberc Lung Dis. 2002;6(9):780-8.

8. Suárez PG, Floyd K, Portocarrero J, Alarcón E, Rapiti E, Ramos G, et al. Feasibility and cost-effectiveness of standardised second-line drug treatment for chronic tuberculosis patients: A national cohort study in Peru. Lancet. 2002;359(9322):1980-9.

9. Subdit Tuberkulosis. TB MDR [Internet]. 2020 [cited 2020 Sep 15]. Available from:

https://tbindonesia.or.id/informasi/te knis/tb-mdr/

10. Gler MT, Podewils LJ, Munez N, Galipot M, Quelapio MID, Tupasi TE. Impact of patient and program factors on default during treatment of multidrug-resistant tuberculosis. Int J Tuberc Lung Dis. 2012;16(7):955-60.

11. Dinas Kesehatan Provinsi DKI. Profil Kesehatan Provinsi DKI Jakarta Tahun 2018 [Internet]. Jakarta; 2018. Available from: https://drive.google.com/file/d/1q3R PnSnLpKqSnYVWf_NWYMwjQ3 BoLSM9/view

12. RSUP Persahabatan. PELAYANAN TUBERKULOSIS RESISTEN OBAT TERPADU [Internet]. 2020 [cited 2020 Sep 15]. Available from:

https://rsuppersahabatan.co.id/layan an-unggulannasional/detail/pelayanantuberkulosis-resisten-obat-terpadurujukan-nasional

13. Akessa GM, Tadesse M, Abebe G. Survival Analysis of Loss to Follow-Up Treatment among Tuberculosis Patients at Jimma 
University Specialized Hospital, Jimma, Southwest Ethiopia. Int J Stat Mech [Internet]. 2015;2015:17. Available from: http://www.hindawi.com/archive/20 15/923025/

14. Moyo S, Cox HS, Hughes J, Daniels J, Synman L, De Azevedo V, et al. Loss from treatment for drug resistant tuberculosis: Risk factors and patient outcomes in a community-based program in khayelitsha, South Africa. PLoS One. 2015;10(3).

15. Dooley KE, Lahlou O, Ghali I, Knudsen J, Elmessaoudi MD, Cherkaoui I, et al. Risk factors for tuberculosis treatment failure, default, or relapse and outcomes of retreatment in Morocco. BMC Public Health. 2011;11.

16. Brust JCM, Gandhi NR, Carrara H, Osburn G, Padayatchi N. High treatment failure and default rates for patients with multidrug-resistant tuberculosis in KwaZulu-Natal, South Africa, 2000-2003. Int J Tuberc Lung Dis [Internet]. 2010;14(4):413-9. Available from: http://www.pubmedcentral.nih.gov/ articlerender.fcgi artid $=3005763 \& \mathrm{t}$ ool $=$ pmcentrez $\&$ rendertype $=$ abstrac $\mathrm{t}$

17. Munro SA, Lewin SA, Smith HJ, Engel ME, Fretheim A, Volmink J.
Patient adherence to tuberculosis treatment: a systematic review of qualitative research. PLoS Med [Internet]. 2007;4(7):e238.

Available from: http://www.ncbi.nlm.nih.gov/entrez/ query.fcgi? $\mathrm{cmd}=$ Retrieve $\& \mathrm{db}=\mathrm{Pub}$ Med\&dopt=Citation\&list_uids $=176$ 76945

18. Masini EO, Mansour O, Speer CE, Addona V, Hanson CL, Sitienei JK, et al. Using survival analysis to identify risk factors for treatment interruption among new and retreatment tuberculosis patients in Kenya. PLoS One. 2016;11(10).

19. Pinidiyapathirage J, Senaratne W, Wickremasinghe R. Prevalence and predictors of default with tuberculosis treatment in Sri Lanka. Southeast Asian J Trop Med Public Health. 2008;39(6):1076-82.

20. Kementerian Kesehatan. Petunjuk Teknis Manajemen Terpadu Pengendalian Tuberkulosis Resistan Obat. Jakarta; 2013.

21. Scano F, Vitoria M, Burman W, Harries AD, Gilks CF, Havlir D. Management of HIV-infected patients with MDR- and XDR-TB in resource-limited settings. Vol. 12, International Journal of Tuberculosis and Lung Disease. 2008. p. 1370-5. 